\title{
Albertus de Colunya. Alemanes en la ciudad de Valencia a mediados del siglo XV
}

\author{
Albertus of Colunya. Germans in the city of Valencia around the middle of the $15^{\text {th }}$ century
}

0

Joaquín Aparici Martí*

Universitat Jaume I. Castelló, España

Fecha de recepción: mayo de 2018. Fecha de aceptación: junio de 2018.

\begin{abstract}
Resumen
En el transcurso del siglo XV, la ciudad de Valencia se configuró como un importante emporio comercial que atrajo negocios, capitales, mercancías, y también personas. Valencia fue un gran centro cosmopolita donde comerciantes y artesanos de toda la geografía europea podían desarrollar sus actividades. A los italianos, que eran la mayoría, unimos ahora los datos recopilados sobre gentes de origen alemán documentadas en la primera mitad del siglo XV, período menos conocido bibliográficamente. A través del uso del método prosopográfico, y a la búsqueda de perfiles sociales definitorios, mostramos como ejemplo de la investigación resultante el caso del zapatero Albertus de Colunya.
\end{abstract}

\begin{abstract}
Over the 15th century the city of Valencia was shaped as a very important emporium that drew business, capitals, goods and some people too. Valencia became a great cosmopolitan centre where merchants and artisans from all the European continent could carry out their works. To the Italians who were majority, we add now all the data collection about Germans researched in the first half on the 15th century, a period less know bibliograficly. Trough the use of the prosopografich method ant the search of defining social profiles, we show as an example of result investigation the case of Albertus of Colunya, a shoemaker.
\end{abstract}

\footnotetext{
* Doctor en historia (medieval), profesor ayudante doctor (II) en la Universitat Jaume I de Castelló (Departament de Pedagogia, Didàctica de les Ciències Socials, la Llengua i la Literatura). Miembro de FORVAL (codi UJI 299) para la investigación en historia medieval, y de EPiCS (codi UJI 300) para la investigación en didáctica de la historia. El texto ahora presentado se vincula a la estancia de investigación invitada y realizada en el departamento de Historia Medieval de la Universitat de València, llevada a término durante 2018. Por otro lado agradezco al profesor David Igual Luís, de la Universidad de Castilla-La Mancha, sus oportunas sugerencias para la realización del presente texto.
}

\section{Palabras clave}

Valencia

siglo XV

inmigración

alemanes

manufactura del cuero
Keywords

Valencia XVht century immigration Germans manufacture of leather 
1. Un cambio de alianzas políticas entre estados, mutaciones en los intereses partidistas de los miembros de las oligarquías locales, medidas proteccionistas ante los "extranjeros", o nuevas medidas impositivas, etc... Una sóla, o algunas en conjunción, podían indicir en un cambio de destino a la búsqueda de situaciones más favorables.

2. En la actualidad, y conjuntamente con el profesor David Igual de la Universidad de Castilla-La Mancha, estamos preparando un trabajo en el que llevamos a cabo la identificación de artesanos y comerciantes de origen flamenco que actuan en Valencia. Mediante el método de investigación prosopográfico hemos podido documentar ya a más de medio centenar de estos flamencos habitando en la ciudad entre finales del siglo XIV y mediados del siglo XV. (continúa en página 193)

3. Hemos mantenido la onomástica tal y como se reproduce en los documentos consultados, sin normalizarla en castellano o valenciano actual.

\section{Motivación}

En el transcurso del siglo XV, la ciudad de Valencia es una urbe densamente poblada. Un gran traspaís rural drena efectivos humanos y también materias primas transformando la ciudad y convirtiéndola en un emporio comercial de primer orden en el ámbito mediterráneo. A su vez, Valencia deviene núcleo de producción de las más diversas manufacturas que encuentran un amplio mercado donde comercializarse. Rutas mediterráneas y atlánticas toman la playa de la gran ciudad, u otras menores pero dentro del ámbito de influencia valenciana, como referentes para dinamizar las transacciones y el intercambio de productos. En definitiva, crecimiento económico y demográfico. Y ello atrae gentes de orígenes geográficos diversos, con oficios variados, personas que tal vez veían limitadas en sus lugares de origen las posibilidades de mejorar sus condiciones de vida o sus negocios, o que tal vez llegaron porque el proceso migratorio formaba parte de las dinámicas socioprofesionales, instrínsecas a su oficio, ${ }^{1}$ como el caso de los mercaderes (Navarro, Igual, Aparici, 1999). Precisamente son los mercaderes, que cuantitativa y cualitativamente resultaron ser muy importantes en la ciudad de Valencia, uno de los grupos más estudiado al respecto. En ese sentido se ha atendido a las iniciativas y perspectivas de negocio, unidas a la transformación estructural que experimenta el sistema de intercambios valenciano desde fines del siglo XIV, pero también a la integración de los canales de la distribución y del sistema agrario a través del mercado (Cruselles, 2007). Pero además se ha estudiado su origen geográfico y las implicaciones que ello conlleva. Así, desde finales del siglo XIV la presencia de comercianes de origen italiano en la ciudad fue en progresivo aumento. Pronto se afianza la presencia de los genoveses, florentinos, pisanos, sieneses o lombardos (Mainoni, 1982; Igual, 1994, 1995 y 1998). Los italianos son la mayoría. Pero de igual manera, desde mediados del XV la presencia castellana fue cobrando importancia en unión con las menciones a operadores alemanes y franceses, ampliándose con ellos el carácter internacional del mercado (y de la cosmopolita ciudad) de Valencia (Cruselles, 1999; Diago, 2002). También la pesencia de mercaderes flamencos queda patente, ${ }^{2}$ con la especial mención a Martín Van der Beurse (Verlinden, 1985), o la red comercial tejida que unía Valencia y Flandes y que sirvió de inspiración a J. Hinojosa para el título de su investigación: "la nave della frutta" (Hinojosa, 2007). Siguiendo los pasos de los comerciantes y mercaderes, o de forma paralela a ellos, los artesanos foráneos iniciaron la misma dinámica migratoria que tenía como punto focal la ciudad de Valencia. Entre ellos podemos destacar el grupo de los inmigrantes trabajadores de la seda, de origen castellano algunos y de origen genovés la gran mayoría, que buscando el mercado laboral creado en la urbe valentina, llegarán a conformar un cuantioso número de profesionales del sector, concentrándose su presencia fundamentalmente en el transcurso de la segunda mitad del XV (Navarro, 1994, 1997 y 1999).

Ahora, la pretensión de estas líneas es poder aproximarnos al grupo de los inmigrantes originarios del centro-norte europeo, concretamente de Alemania, que pudieron llegar a Valencia atraídos por las posibilidades de negocio existentes, o simplemente atraídos por la posibilidad de mejorar su calidad de vida. ${ }^{3}$ Debemos tener presente que la zona de Flandes-Alemania suponía el límite máximo de la relación económica de la propia ciudad de Valencia. La presencia de miembros de aquel origen geográfico está documentada y existen referencias bibliográficas al respecto, si bien la tendencia general es a concretizar las investigaciones respecto a las grandes compañías comerciales como la Ravensburger (Schulte, 1923; Hinojosa, 1987), la creación de un derecho específico que gravaba el comercio de los alemanes (López, 1976), o centrarse preferentemente en la segunda mitad del siglo XV e inicios del XVI, período del que se conserva un mayor volumen documental, que coincide con un mayor desarrollo económico y demográfico de la ciudad de Valencia, y que hipotéticamente también coincide con una presencia más mayoritaria de este grupo (Hinojosa 1976, 2002 y 
2007; Kellenbenz, 1988; Diago, 2002). También existe un estudio de síntesis que interrelaciona la presencia de los mercaderes alemanes en Barcelona, Zaragoza y Valencia (Casado, 2015). Por ello, ahora trataremos de cubrir un poco el espacio yermo, por ser más desconocido documentalmente, ahondando en el margen cronológico de la primera mitad del siglo XV. Y necesariamente hemos de detenernos en la documentación de la ciudad de Valencia, no sólo por ser el centro económico y financiero en el transcurso de dicha centuria y conservar abundante documentación (especialmente protocolos notariales) para el período de estudio, sino porque el resto del territorio parece ser no captó especialmente la atención de los alemanes ahora estudiados (excepción hecha del sur, Alicante), ni tampoco disponemos de documentación tan abundante y seriada. Por ejemplo, en la zona de la Plana de Castelló, situada al norte de Valencia, se ha podido documentar la presencia de mercaderes y artesanos franceses, portugueses, italianos, vizcaínos o navarros, pero ningún alemán (Aparici, 2016). En ese sentido, algunos autores apuntaron en su momento que aunque en Valencia esporádicamente se localizase a algún que otro alemán en la primera mitad del XV, podía concluirse que, en general, su escasa actividad en los mercados levantinos, financieros y mercantiles, respondía al sólido control que los operadores italianos habían adquirido sobre los procesos de distribución adscritos a este circuito mercantil. Y precisamente, sólo se ha podido atestiguar la creciente presencia de factores y comerciantes alemanes en Valencia, pero a finales del siglo XV (Cruselles, 1988-89 y 1998). Con todo, esa idea se puede matizar. M. Diago menciona un guiaje otorgado por el monarca Fernando I en 1415 a ocho mercaderes de origen alemán, en el que se incluía la ciudad de Valencia (Diago, 2002: 304).

Para poder llevar a cabo esta investigación se han consultado diversos protocolos notariales conservados en el Archivo del Real Colegio del Corpus Christi de Valencia (APPV), recopilando informaciones variadas sobre los alemanes que, de una u otra manera, concretaron actos ante alguno de los notarios cuyos registros escritos sí se han conservado. Y mediante la prosopografía como método de investigación, tratamos de reconstruir aspectos de la vida de nuestros protagonistas, acumulando el máximo posible de noticias para, después, trazar elementos comunes a cada una de las prosopografías obtenidas acercándonos así tanto a la realidad individual del personaje, como a los caracteres que en común pueden ejemplificar diversos perfiles sociales. ${ }^{4}$

\section{Alemanes en tierras de la Corona de Aragón}

Para los oriundos alemanes, el camino hacia los territorios ibéricos y mediterráneos podía seguir básicamente dos rutas. Una, marítima, partía de los puertos del norte y entraba en conexión con los Países Bajos y también con las galeras mediterráneas, especialmente las venecianas, que llegaban a esas latitudes. La otra ruta, terrestre, permitía a los alemanes de la zona meridional atravesar los pasos del valle del Ródano, y continuar camino terrestre hacia los Pirineos, o llegar a Génova u otro puerto y embarcar hacia la costa catalana, mallorquina o valenciana. O simplemente, quedarse en esa zona del norte italiano, en ciudades como Florencia, o más al este Venecia. ${ }^{5}$

Por lo que se refiere a los territorios ibéricos en opinión de Kellenbenz tal vez la documentación más antigua sobre contactos mercantiles alemanes en esta geografía sea la del mercader de Nüremberg Ulman Stromer, con su memorial de gastos en la aduana de Barcelona, acompañado a su vez de varias menciones a mercaderes alemanes en esta ciudad contenidas en protocolos notariales del año 1372, a los que se unen menciones, también de fines del siglo XIV, a artesanos, como la del zapatero de Colonia Conrad Brost que en 1396 quería ser enterrado en el convento de
4. Véase por ejemplo el dosier La prosopografía como método de investigación sobre la Edad Media, publicado por el Departamento de Historia Medieval, Ciencias y Técnicas Historiográficas y Estudios Árabes e Islámicos de la Universidad de Zaragoza (2006) con aportaciones sobre Aragón realizadas por Germán Navarro, José A. Sesma Muñoz y Carlos Laliena; sobre Italia con Gabriella Piccinni o Alessandra Veronese; sobre Castilla con María Asenjo o Pascual Martínez; sobre Portugal con Luís Miguel Duarte; o sobre Navarra con Eloísa Ramírez.
5. La presencia de un considerable número de alemanes atraídos por el desarrollo de la actividad productiva textil de la lana en Florencia se documenta en el paso del siglo XIV al XV (Franceschi, 1999). En la misma ciudad, el libro registro de legados testamentarios, datable entre 1413 y 1456 , mostraba que el $40 \%$ de los extranjeros allí consignados eran originarios de tierras alemanas. Pero también el listado de 1436 "dell'Ufficio dell'Onestà“ recogía el nombre y origen de 71 prostitutas precisando que 26 provenían de la zona de los Paises Bajos y otras 16 eran de origen alemán,

(continúa en página 193) 
6. Precisamente el azafrán y su comercio por parte de mercaderes alemanes afincados en Barcelona es en los últimos años objeto de investigación utilizando como fuente documental las series conservadas relativas al derecho alemán y saboyano entre 1425 y 1445 (Casado, 2014; 2014-2015; 2015).
7. Por ejemplo, la presión ejercida por la Busca sobre la Biga para acometer medidas proteccionistas provocará la prohibición de 1442 sobre la introducción de los fustanes de origen alemán en la ciudad de Barcelona, a fin de proteger y fomentar la manufactura propia. La Biga acabó retirando esa prohibición en 1448 , pero cuando en 1453 la Busca asumió el poder, el comercio alemán se desplomó (Casado, 2015: 163). agustinos de Barcelona (Kellenbenz, 1988: 246-247; Mitjà, 1958: 213 y 1962-63). De estas noticias parece desprenderse la presencia efectiva en Barcelona a fines del XIV de gentes originarias de Alemania, tanto comerciantes como artesanos. Con toda probabilidad su número creció progresivamente a inicios del XV y tal vez por ello, por su creciente actividad mercantil, se hizo necesaria la regulación de su actuación a través de un nuevo gravamen, el "Dret alemany e saboià" (López, 1976). Así, el 7 de enero de 1420, el rey Alfonso V les obligaba a pagar un derecho de 4 dineros por libra del valor que afectaría a toda mercancía que, dentro de los territorios de la Corona de Aragón, fuera traficada directamente por alemanes y saboyanos, o por cualquier otra persona que lo hiciese en su nombre, y que afectaba a las fronteras interiores de los diversos territorios de la Corona, pero también a las fronteras exteriores, tanto en importación como en exportación.

Da la impresión de que Barcelona comenzó a ser una importante base de negocios para los mercaderes alemanes, base que se fue consolidando a lo largo de la centuria. Así parece confirmarlo un listado de ese derecho real datado en 1443 (y conservado en Barcelona) donde se menciona a varios mercaderes alemanes (Jous Hompis, Johan de Colunya, Gaspar de Vat o Jaume Rostenegater de Ulm) importando productos textiles, como lienzos de Suavia, fustanes, telas y cañamazos de los Países Bajos, así como también metal. Mientras, de forma paralela y en el lado de las exportaciones destacaba como producto principal el azafrán (Schulte, 1923: 513-516). Los mismos protagonistas documentados por Schulte se repiten en los listados de la lezda barcelonesa de una década antes, en 1434, con Johan de Colunya, Jous Hompis y Gaspar de Vat, quienes se inclinaron preferentemente, como decimos, por la exportación del producto estrella: el azafrán peninsular (Salicrú, 1995: 181). ${ }^{6}$

Pero más allá de los comerciantes, otros estudios han rastreado la presencia en Barcelona de toda una pléyade de individuos de origen germano, con oficios y actividades variadas, destacando el grupo de los escultores documentados en el transcurso de la segunda mitad del siglo XV e inicios del XVI, entremezclados con otros oriundos de esa misma geografía con oficios artesanos como guanteros y libreros, o dedicados a actividades religiosas y vocacionales, como los frailes (Jardí, 2006 y 2007-08). De hecho, el rastreo en el Archivo Histórico de Protocolos de Barcelona ha permitido identificar a más de un centenar de alemanes a fines de la centuria. Además, en 1490 aparecen los primeros legados de alemanes a favor de un "tumulo vocatur dels alemanys" en la capilla de Santa Bárbara, sita en el claustro del monasterio de los frailes predicadores de Barcelona, espacio que posiblemente sustituyó como punto devocional al convento de los agustinos. Incluso, con fecha de marzo de 1492, se conserva el documento real de aprobación de las ordenanzas de la cofradía de los alemanes en Barcelona, bajo advocación de Santa Bárbara (Jaspert, 2005: 1788-1789).

Sin embargo la inestabilidad socio-política y económica derivada inicialmente de la lucha intestina por el poder municipal en Barcelona entre la Busca y la Biga, y poco después por la guerra civil catalana, pudo provocar que en la década entre 1450 y 1460 se produjese una reorientación de las bases de actuación de aquellos comerciantes alemanes que, desde Barcelona, pudieron encontrar en Valencia o en Zaragoza un nuevo centro desde donde organizar sus negocios. ${ }^{7}$

El territorio aragonés no era desconocido para los alemanes. Aquellas tierras eran un importante centro productor de azafrán, y los mercaderes germanos ya actuaban allí desde mediados de siglo. Los mismos comerciantes que aparecen en Barcelona se documentan en Zaragoza en una dinámica similiar de exportación, como pone de manifiesto el registro zaragozano de 1430. En este documento, los 57 ítems que muestran la salida de mercancías desde Zaragoza hacen referencia exclusiva al azafrán, si bien en algunos de los ítems el declarante indica que compró el producto en 
Cataluña, hacia donde es remitido para que abone el impuesto. Por ejemplo, en diciembre de 1430, "Jous Hompis manifestà que havia compraten Cathalunya" 195 libras de azafrán, y que "fonch remés a Barcelona per pagar lo dret" (Schulte, 1923: 507-510). Otras fuentes, notariales, nos muestran que junto a dicho producto desde Aragón también se exportaron lanas y pieles, mientras que las importaciones se basaban especialmente en productos textiles y metales. En 1472 se documenta un salvoconducto concedido por los diputados aragoneses a favor de los mercaderes alemanes Jos Hompis, Johan Destlarch, Jacob Rodolf Polispich y Johan Galdrich, y sus compañías, factores, trajineros, mozos, etc... para poder vender sus mercancías en el reino de Aragón (Navarro, 2016: 258). En los años 90 del siglo XV se documenta en Zaragoza la actuación de comerciantes como Jacob Ehinger o Wolfgang Ferber (Kellenbez, 1988: 249-250); Clemens y Conrad Angarrita, Johan Feliz, Gabriel Gaster de Ravesnsburg, Conrad Hillenson, Jos Hompis, Johan Risch de Cura, Gabriel y Polai Steinhussler, Gaspar Vizlant de Isny, o Gaspar Vonbull de Sant Gall (Navarro, 2016: 257-258); o en las localidades de Muniesa y Daroca a los alemanes Alois y Gaspar Solicofer adquiriendo azafrán (Martínez, 2012: 322-324). Precisamente el azafrán aragonés, y la venta en estas tierras de productos textiles alemanes, fueron elementos que suscitaron el interés de aquellos comerciantes por asentarse en Zaragoza, teniendo en cuenta su coyuntural presencia por el traslado desde Barcelona como resultado de la guerra civil catalana. Y como en Barcelona, también en Zaragoza encontramos oficios varia$\operatorname{dos}^{8}$ y artesanos especializados, caso por ejemplo de los diez impresores y seis libreros alemanes (Navarro, 2009), oficio muy específico este último que paralelamente se documenta mucho más al sur, en Sevilla (Bello, 1993).

Y al igual que hacia Zaragoza, la perspectiva de negocio también apuntó hacia Valencia. De hecho, ya en diciembre de 1445, los jurados de esta última ciudad escribieron una carta a los consejeros de Barcelona pidiéndoles que, en cierta manera, protegieran de vejaciones y celos infundados o maltratos a los mercaderes alemanes (se menciona nuevamente a Jous Hompis, Gaspar de Vat y Johan de Colunya) porque sus negocios generaban un amplio beneficio que redundaba a su vez en el acrecentamiento de las arcas del rey y de la cosa pública (Schulte, 1923: 517-518). Cuando en 1481 se produjo una modificación en la tarifa aduanera sobre el "Dret alemany e saboià", que ahora gravaba la importación con unos cánones de hasta el 50\%, el cambio parece ser que incentivó a las compañías alemanas como la Ravensburger para decidirse a abandonar Barcelona en busca de nuevos aires, quedando con todo algunos mercaderes de forma individual (Kellenbenz, 1984: 248). Por ello, cuando el viajero alemán Jerónimo Münzer llegó a la ciudad condal en 1494, mencionó la presencia de un pequeño núcleo de alemanes, como Georg Rasp de Ausburgo, Erhart Wigant de Mergentheim, o Wolfgang Ferber de Ulm que lo agasajaron de forma sublime. Y el mismo Münzer apostillaba que, hacía ya algún tiempo, unos 50 años, la principal parte del comercio se había ido trasladando desde Barcelona hacia Valencia (Puyol, 1924: 49).

Desde 1472 la presencia de la compañía Ravensburger en Valencia actuó como eficaz elemento de atracción para jóvenes alemanes que llegaron a esta ciudad para perfeccionar sus conocimientos en técnicas mercantiles bajo la dirección de los factores de dicha compañía, como Jos Coler, quien según Münzer fue la persona que dotó económicamente al monasterio del Vall de Jesús en Valencia, espacio donde se reunieron algunos germanos, como un sobrino de Thielbald Bucklin, el factor principal de la compañía Ravensburger en Valencia, que fue amigo y albacea testamentario del también alemán Jaume Vizlandt, que falleció en dicho monasterio (Kellenbenz, 1988: 251; Montiel, 2004: 139; Puyol, 1924, 59). Coler no sólo había financiado la reconstrucción del monasterio, sino que además había ordenado la fabricación de la sillería del coro que debía ser tallada e importada desde Flandes. Como vermos más adelante, Coler está documentado en Valencia desde 1435, siendo factor de la compañía Ravensburger (Jaspert, 2005: 1793).
8. Entre otros, por ejemplo, se documenta el 13 de abril de 1425 , en Zaragoza, a Anequi de Bues, halconero de origen alemán, quien reconoció haber recibido de manos del judío Zecri Abenavez, por orden de don Federico de Aragón, Conde de Luna y señor de la ciudad de Segorbe (sita en Castellón), 8o florines precio de 2 halcones. Archivo Municipal de Segorbe (AMS), Libro de Escribanía del Conde de Luna, sig. 215, f. 157r. 
9. Martín de Perugia reconoce que Meliç le ha dado 36 florines como salario de dos años que estuvo a su servicio para vender productos de mercería (Hinojosa, 2007: 272, 286, 434).

10. Ambos son testigos en un acto entre el flamenco Martín Borsa y el alemán Meliç Baltasar (Hinojosa, 2007: 286).

11. Mercader alemán negociante en Valencia, recibe licencia (continúa en página 193)

12. Tendero alemán originario de Brabante. En 1432 enviaba arroz a Colliure y Génova. (continúa en página 193)

13. Mercader alemán consignado en el resgistro de Martí Borsa el 17 de septiembre de 1417 (Verlinden, 1985: 271).

14. Mercader natural de Ravasburch, obispado de Constanza en Alemania. (continúa en página 194)

15. "Botiguer" natural de Nuremberg del Imperio Alemán. (continúa en página 194)

16. "Corretger" natural de Colonia, del Imperio Alemán. (continúa en página 194)

17. “Alamani”. Difunto esposo de Margarita, quien contrae segundas (continúa en página 194)

18. "Mercatore de Alamania presenti in dicta civitate". Margarita de Colunya, viuda de Guriçi Denbós, "alamani", se coloca en matrimonio con Breda,

ofreciendo como dote 500 florines (continúa en página 194)

19. Mercader alemán. Aparece el 9 de mayo de 1417 consignado en el registro de cuentas del mercader

flamenco Martí Borsa

(continúa en página 194)

20. Posiblemente sea el Ubel de Colunya que menciona Hinojosa

en 1434

(continúa en página 194)

21. Mercader alemán residente en Valencia.

(continúa en página 194)

22. "Mercator alamanus Valentie mercantiliter residens". Confesó que Albertus de Colunya le había pagado 30 florines precio de 10 candelabros de "llautó". APPV, prot. 18416 (1452, enero 14).

23. "Botiguer seu mercator alamano Valencie residente". (continúa en página 194)

24. "Botiguerio naturalis Alamania, nunch Valence residenti, presenti”. (continúa en página 194)
$\mathrm{Al}$ igual que en Barcelona, en Valencia la compañía importaba lienzos y textiles, artículos metálicos y de latón. Alemania y Flandes eran los límites máximos de la relación económica de Valencia hacia el norte de Europa (Hinojosa, 2002 y 2007). Por otro lado Valencia exportaba productos agrarios que mostraban el dinamismo de su hinterland rural, como el azafrán, el vino, el arroz, limones, almendras, pasas, y especialmente también el azúcar. La propia compañía Ravensburger disponía de un ingenio o trepiche en el Real de Gandía y mantuvo una activa producción y comercio en las décadas finales del XV (Schulte, 1923; Hinojosa, 1987). A todo ello se unían los productos relacionados con el vector manufacturero que mostraban el dinamismo económico de la zona, ofreciendo materias primas como la cera, la grana, la lana, las pieles y los cueros, pero también productos acabados como telas de la tierra o productos cerámicos. Pero nuevamente, el dinamismo detectado en la segunda mitad del siglo XV sufrió cierto freno. Entre 1482-1483 surge cierto conflicto entre los munícipes de Valencia que pretendían prohibir la venta al detalle de los extranjeros, a fin de beneficiar a los naturales. Pero el rey Fernando II se opuso por cuanto afectaba, especialmente, al comercio alemán. De hecho, la presión ejercida por los factores de la compañía Ravensburger que poseían una tienda en la ciudad, consiguieron que aquella prohibición fuera derogada, al menos en parte. El consejo municipal de Valencia autorizó entre 1487-1488 a los alemanes a vender toda clase de paños, productos textiles y quincallería en las diversas tiendas que poseían en la ciudad (Llop, 1970; Hinojosa, 1987: 459). Y en 1494 Jerónimo Münzer también conoció en esta urbe a un par de compatriotas, mercaderes de profesión, como Enric Sporer y Conrad Hompis, y en Alicante al también germano Iodoc Schedler (Puyol, 1924: 62 y 72). También se documenta el fallecimiento en 1490 del mercader alemán Hans Rix, tras habitar en la ciudad durante cuatro años. Incluso a fines de siglo destaca la presencia en la capital levantina de algunos profesionales de origen alemán relacionados con la imprenta (Rubió, 1993: 215-243) como el anteriormente mencionado Jaume Vizlandt, situación similar a la mencionada en Zaragoza, Sevilla o en Barcelona.

Así pues, la propia visión que ofrece el viajero alemán Münzer invita a pensar que en la Valencia de mediados del siglo XV se estaba fraguando la presencia de los comerciantes alemanes y que esta se consolidó en las décadas siguientes. Pero como hemos dicho más arriba, en la primera mitad del siglo XV ya se muestra su presencia. Así, hemos hecho mención a un guiaje otorgado por el monarca Fernando I en 1415 a ocho mercaderes de origen alemán, en el que se incluía la ciudad de Valencia (Diago, 2002: 304). No en vano Hinojosa, siguiendo en parte el trabajo de Verlinden, documenta en la ciudad de Valencia durante la primera mitad del XV al mercero Meliç Baltasar (1421-1423), ${ }^{9}$ los mercaderes Joan Blanch y Miquel Leopart $(1423),{ }^{10} \mathrm{el}$ también mercader Christófol Spindoli (1426), ${ }^{11}$ el tendero Anrich Infant (1432-1441), ${ }^{12}$ un tal Ubel de Colunya (1434) y en 1451 a un desconocido judío de origen alemán (Hinojosa, 1976: 81-82). Por su parte Verlinden identifica también al mercader Hans van Cuelen (1417). ${ }^{13}$ Además, en los avecindamientos oficializados ante los munícipes valencianos y recopilados por L. Piles, figuran otros dos comerciantes, el mercader Jans Goldequer $(1433)^{14}$ y el tendero Jordi Oliver $(1448),{ }^{15}$ a los que se une un artesano, el correero Enrich Cuix (1431). ${ }^{16}$

A todos ellos, y tras la recopilación prosopográfica, nosotros podemos unir a Gurici Denbós (1413), ${ }^{17}$ los mercaderes Joan de Breda (1413), ${ }^{18}$ Gabriel Rigolf $(1417-1430),{ }^{19}$ Abel de Colunya (1425-1434), ${ }^{20}$ Jos Coler (1446-1450), ${ }^{21}$ Armandus de la Capella (1452), ${ }^{22}$ Enrich Lema (1463), ${ }^{23}$ o el tendero Michaelis de Tro (1445). ${ }^{24}$

Pero además, junto al desarrollo comercial de la ciudad levantina, también el desarrollo manufacturero muestra una conexión constante con el norte europeo. La evolución del sector textil valenciano determinará a los munícipes a presentar una serie de provisiones que tenderán a regular la actividad de tejedores, pelaires, 
tintoreros o bataneros a inicios del XIV, con la concreción de una producción al estilo de los paños franceses. A fines de la centuria las nuevas disposiciones municipales (1385 y 1392) muestran ordenanzas en las que el municipio permite la imitación de paños a la manera de Bruselas y de Werwicq, siendo éstos últimos conocidos como "vervins" o "valencians fets a la vervina". Finalmente, en 1403, las autoridades aprueban la elaboración de paños mayores de Flandes (24nos y 26nos) dejando importar incluso lana inglesa para llevar a cabo las primeras experiencias (Iradiel, 1986). El fenómeno se repetía al norte de Valencia, en Castelló, donde una ordenanza municipal de 1385 permitía "obrar o fer obrar draps atinent forma e aparell de Virvi" (Iradiel et alii, 1995). Por ello, la presencia de paños del norte europeo, o paños a imitación de éstos, resulta patente en la documentación valenciana. Así, en 1395, entre los bienes del difunto mercader florentino residente en Valencia Matheo Francisci, se listaba "un caperó vermell de verví de Flandres, unes calces de drap vert oliver de verví de Flandres, altre caperó vert de drap de Ypré, un caperó blau de Mallines". Ese mismo año, entre los bienes del difunto pelaire Joan Çagarriga se listaban "quatre draps blaus de verví esbroats, ítem una manteta de dona de drap de Melines blau forrada, ítem altre caperó de drap d'oliver de verví de Flandes". ${ }^{25}$ Y poco a poco, entre estos paños del norte de Europa, desde finales del siglo XIV aparecen los productos alemanes (paños imperiales y de Colonia). ${ }^{26}$

Uno de los ejemplos más ilustrativos al respecto lo documentamos en 1429 a través del inventario de bienes del difunto "brunater" de Valencia Francesc Segarra, inventario en el que se lista un cuantioso número de paños y telas, diferenciándose claramente los "draps de la terra" y otros que son "peces de drap castella", de aquellos otros adjetivados como alemanes y holandeses, entre los que también se mencionan toallas y sombreros. ${ }^{27}$ La presencia de esos paños alemanes, de Colonia, Imperiales, etc... sigue presente en la documentación valenciana con una cronología posterior. Recordemos que en 1506 el comercio de artículos textiles procedentes de la Alemania meridional, Holanda y Milán, suponía el $65 \%$ de la actividad de la compañía alemana Ravensburger, y que la compañía de los Ankenreute mantenía un volumen de negocios similar (Hinojosa, 1987: 465-466. Cruselles, 1998: 253).

Más allá de la adjetivación de telas con ese origen geográfico, en alguna ocasión hemos podido documentar otros elementos tildados de tal manera. En 1442 el pintor valenciano Manel Lópiz reconocía que Galcerà d'Exarch, mercader de Valencia y clavario de redención de censales y administración de obras de la cámara dorada de la sala del consejo, le había pagado 49 libras 9 sueldos 9 dineros debidos del precio de 15 libras y 3 cuartos de onza "de atzur fi de Alamanya", pigmento para la realización de la obra de arte. ${ }^{28}$

Así pues, junto a los comerciantes, también en Valencia documentamos la presencia de artesanos de origen alemán. Como hemos visto, ya L. Piles documentó a un correero llamado Enrich Cuix en 1431. Nosotros podemos unir a otros menestrales como los zapateros ("cerdoni") Albertus de Colunya (1439-1463+), Ans Alegre (1451-1452) ${ }^{29}$ y Jaume de Liega (1451), ${ }^{30}$ el bolsero ("bosser") Nicholau Derich (1439), ${ }^{31}$ el espadero Johan de Colunya (1444), ${ }^{32}$ el guantero Rotlandus de Salamó (1450), 33 el argentero Joan de Utrech (ya difunto en 1450), 34 o el maestro de hacer órganos Pere de Res (1450). ${ }^{35}$ Como vemos, muchos de ellos vinculados, no al sector textil, sino al del cuero y la metalurgia.

\section{Albertus de Colunya, maestro zapatero alemán.}

Tras observar las referencias bibliográficas y documentales existentes relativas a los alemanes presentes en Valencia, nuestra pretensión es ahora poder aproximarnos a
25. APPV, prot. $14091(1395$, octubre 25 ), prot. 869 (1395, julio 21 ). También en 1409, el caballero valenciano Guillem Benet confesaba deber al pañero Jaume Monçó 25 libras 15 sueldos "racione panni lane de Flandes diversorum collorarum" cancelándose en 1412. (continúa en página 195)

26. Entre los bienes del mercader valenciano Andreu Lópiç, en 1395 , se mencionaban varios paños que formaban parte de la sociedad con el florentino Goro d'Estagio (continúa en página 195)

27. Así por ejemplo, se mencionan: "ítem quatre camisses d'om de tela d'Alamanya pus prima, ítem quatre camisses d'om de tela d'Alamanya pus prima, (continúa en página 195)

28. APPV, prot. 28472 (1442, marzo 10).

29. "Magistro cerdone alamanus" habitante en Valencia. En agosto de 1451 confesó deber a Albertus de Colunya, "cerdo" de Valencia, 80 libras que en su nombre había pagado por ciertos cueros para su tienda y otras cosas

(continúa en página 195)

30. "Cerdo alamanus Valencie residens". Junto a su esposa Gallarda, que anteriormente fue sierva del mercader valenciano Martí Torrozella, confiesa que éste les ha pagado 13 libras debidas a Gallarda por los servicios prestados en su casa. APPV, prot. 18416 (1451, junio 7). 31. "Bosser alamany resident" en Valencia. Figura como uno de los albaceas testamentarios del ciudadano Jaume Perfeta. APPV, prot. 20707 (1439, junio 13).

32. "Spaserius regni Alamanie, pro nunch Valentie degentem". Es nombrado procurador por Joan Iter, espadero del reino de Francia residente en Valencia. APPV, prot. 18415 (1444, agosto 25 ).

33. "Guanterius alaman" de Zaragoza residente en Valencia. Teniendo causa de cesión del difunto Joan de Utrech, argentero alemán de Valencia, nombra procurador a Mateo Munyoç, batihoja, ausente, para recibir ápocas y derechos. APPV, prot. 23656 (1450, octubre 26).

34. Argentero alemán residente en Valencia. Difunto ya, el guantero alemán de Zaragoza residente en Valencia Rotlán de Salamó indica tener causa de cesión de Joan respecto a su hermano Gerard de Utrech,

(continúa en página 195)

35. "Alamany, mestre de fer órguens natural de la vila de Res comorant en València". Contratado con Gabriel de Benviure mercader, y Mateo Livia curtidor, ambos obreros de la iglesia de Santa Creu, (continúa en página 196) 
36. Para evitar la farragosidad de las referencias archivísticas, las ubicamos en su conjunto en la presente nota. APPV, prot. 18415 1444, junio 12; agosto 12; octubre 7; noviembre 5), prot. 25971 (1446, enero 21$)$, prot. 16704 (1448, enero 12; febrero 7; mayo 9; octubre 25; noviembre 22), prot. 20716 (1448, septiembre 11), prot. 18416 (1451, febrero 13; marzo 3; abril 12; agosto 7; octubre 21; noviembre 20 y 24 ; diciembre $29 ; 1452$, enero 14 y 27), prot. 29041 (1451, diciembre 9), prot. 18414 (1457, marzo 15; septiembre 7; octubre 13 y 26 ; 1458 , julio 10$)$, prot. 16706 (1461, julio 9; 1463, marzo 29). la realidad cotidiana de un artesano inmigrado, y para ello presentamos una de las prosopografías compiladas, la del zapatero Albertus de Colunya. ${ }^{36}$ Calificado en la documentación como "magistro cerdoni", Albertus era natural de la ciudad alemana de Colonia. Aún así, pronto será tildado como ciudadano de Valencia. Se conserva el acto de avecindamiento oficial datado el 14 de abril de 1439 en el que se especifica que lo hace por tiempo de 10 años (es decir, oficialmente hasta 1449), habitando en la Parroquia de Santo Tomás, siendo su fiador el mercader valenciano Galcerá Martí (Piles, 1978: 1112). Albertus pasa a ser un habitante más de la gran ciudad hasta su fallecimiento en 1463.

En los años posteriores a su llegada sabemos que actúa como testigo en varias ocasiones durante 1444 y 1448 . Pero paralelamente en otros momentos Albertus es parte activa en el contrato o convenio. En estos documentos observarmos como nuestro protagonista está inmerso en la actividad productiva en la que se mueve, el cuero y los zapatos, pero también que su círculo social está próximo e imbrincado con el de otros inmigrados del mismo origen.

Así, a nivel profesional, el 21 de enero de 1446 el zurrador ("assaonator") de Xátiva Jaume Rausell, junto a Albertus, confesaba deber a Joan Valleriola, mercader ciudadano de Valencia, 27 libras 7 sueldos 6 dineros precio de 30 docenas de pieles de "remudes" a pagar hasta marzo, si bien Rausell reconocía que las pieles eran para él, manteniendo indempne a Albertus. Como vemos, Albertus mantiene relación con un profesional del mismo sector productivo, y en un contrato de compra de materia prima. Pero también fabrica y vende zapatos. El 21 de octubre de 1451, Albertus, por similar cantidad que él debe a Gerard Fruch, jubonero ("giponer") habitante en Valencia, le cede los 87 sueldos 9 dineros que a Albertus debían los herederos de Pere Alegre, ciudadano de Valencia, por razón de calzados. También en marzo de 1457, el noble Joan de Vilanova confesó deber a Albertus 15 libras precio de diversos calzados para él y para los miembros de su casa, a pagar durante dicho mes. De hecho, en septiembre de ese año, y para resarcir a su esposa Isabel de las 80 libras que le aportó en dote más las 40 libras de aumento, Albertus le vende los bienes muebles que había dentro de su casa, entre los que destacan numerosos pares de zapatos de hombre, mujer, niño, chapines, hormas de zapatos, herramientas del oficio, pieles, etc... (véase anexo, documento 1 ).

Posiblemente viculado con sus intereses como zapatero, el campo de actuación de Albertus se extendía fuera del propio reino de Valencia. En febrero de 1451, Albertus revocó como procurador de sus asuntos en Mallorca al "cerdo" Pere Molins, sustituyéndolo por el notario mallorquín Bernat Ferrer. Poco más tarde, en marzo, ratifica la revocación de Molins y nombra un nuevo procurador para sus asuntos en la isla, con la misma profesión que él, "cerdo", en la persona de Baudet Daynés, vecino de la ciudad de Mallorca. Todavía dos años más tarde, en 1453 Albertus está documentado en la isla (Vaquer, 1995).

Albertus se había avecindado en Valencia en la Parroquia de Santo Tomás. En dicha parroquia compró una vivienda. El 15 de junio de 1448 Lluís Fuster tejedor de velos de Valencia, junto a su esposa Úrsula, vendieron a Albertus un hospicio sito en la Parroquia de Santo Tomás, bajo censo de la cofradía de "Òrfenes a maridar" (huérfanas en edad de matrimonio) con censo de 10 sueldos. El precio de la venta fue de 3.500 sueldos. Pero la inversión inmobiliaria era más amplia. En 1451 figuraba como propietario de otra vivienda que, en su momento, debió adquirir junto a su primera esposa Raymunda. Así, en noviembre de ese año, Joan Fuster, presbítero beneficiado en la Sede de Valencia, en el beneficio dedicado a San Benet en la iglesia de Santa Caterina y San Leonardo, habiendo dominio directo sobre la casa de Albertus sita en la Parroquia de Santa Caterina, inmueble con un censo de 150 sueldos pagaderos 
en Todos Santos a dicho beneficio, le da permiso para cargar un retrocenso que no exceda de 50 o 60 libras, comprometiéndose Albertus a quitar dicho retrocenso en un máximo de 4 años. Pocos días después, el 9 de diciembre de 1451, Albertus, en su nombre y en calidad de heredero de su difunta esposa Raymunda, vendió a Domingo Catalá, ciudadano de Valencia, 90 sueldos de retrocenso sobre ese hospicio sito en la Parroquia de Santa Caterina, frente la curia del consulado de Valencia, precio de 60 libras.

El hecho de cargar un retrocenso sobre la vivienda, que es la garantía de pago, nos muestra la necesidad de solvencia económica que pudo afectar a Albertus en un determinado momento, como a tantas otras personas, y obligarle a la búsqueda del numerario efectivo para solucionar cualquier incidencia. Y con ello, entrar en la dinámica crediticia de los censales y violarios. Pero no era la primera vez. El 9 de mayo de 1448, Just de Capmanyes, doctor en leyes de Valencia, confesó que Albertus le había pagado 42 sueldos 10 dineros que son parte de los 85 sueldos 8 dineros restantes a pagar de la pensión de violario que Albertus, junto a Andreas de Bruxelles, le hacen cada año en dos mitades, y que pertenece a la pensión de abril. Y años más tarde, en octubre de 1457, Albertus vendió al mercader valenciano Luís Castelló 54 sueldos 4 dineros de violario precio de 19 libras.

Por otro lado, recordemos que Albertus era alemán. La primera toma de contacto del foráneo con el nuevo espacio al que llega puede, en ocasiones, ser desalentadora o resultar traumática. A fin de evitar esa situación, pueden desarrollarse toda una serie de estrategias de acogida que faciliten, al máximo posible, la inserción del recién llegado en el tejido social y económico en el que se encuentra. Podemos detectar redes de solidaridad que facilitan el proceso utilizando a miembros de la misma familia, también a oriundos de la misma geografía de origen, o también, en ocasiones, a profesionales del mismo sector productivo. Si seguimos estos modelos, sí se perciben esos lazos de solidaridad y ayuda entre los miembros de una misma geografía de origen, y no sólo como elemento canalizador de la socialización del individuo, sino también como elemento de pertenencia, identidad y protección de un pequeño grupo, el alóctono, inmerso en el marco envolvente del grupo más numeroso, el de los autóctonos. Cuando el alemán Jerónimo Münzer visitaba Barcelona, Valencia o Alicante, era acogido, como ya hemos visto, por sus compatriotas. Se situaba entre sus naturales. También a través del análisis del testamento y codicilo del flamenco Martín van der Beurse, E. Cruselles indicaba que aquél se movía en un estrecho círculo de compatriotas. Su heredero era su primo Jordi de la Bossa, sus tres albaceas eran flamencos o alemanes, e incluso se menciona a otro compatriota residiendo con él. Por tanto, y en opinión del citado autor, se percibe un escaso grado de integración de este comerciante brujense en la sociedad local (Cruselles, 2007).

En nuestro caso, en la Valencia de la primera mitad del siglo XV, los posibles entramados de socialización del individuo se visualizan de diferentes formas. Por un lado, siguen mostrando la relación entre miembros de la misma comunidad, como una especie de círculo cerrado al estilo de lo descrito por E. Cruselles para el flamenco Beurse. En 1413 el mercader alemán Joan de Breda se casó con Margarita de Colunya (significativo apellido), quien era viuda del también alemán Gurici Denbós. Testigo del acto fue, curiosamente, un tal Guillermus d'Alamanya (otra vez el apellido), fraile menor de Valencia. Como vemos, todos los implicados parecen tener el mismo origen geográfico. Pero también es cierto que el enlace matrimonial con autóctonos pudo servir para conseguir una mejor integración en la sociedad de acogida, como veremos con Albertus o con Ans Alegre.

En ese sentido, Albertus no descuidó la atención hacia los que podía considerar como sus compatriotas del norte. Hemos visto como en 1448 compartía el pago de un 
37. El 29 de diciembre de 1451 Albertus, junto al correero Thome Taverner, actuaba en calidad de procurador de Anthonete, doncella hija de maestro Nicholai de Champanya, del reino de Francia, cuando ésta recibía su soldada por haber servido en casa del mercader valenciano Lluís de Sentángel, actuando también ese día como a procurador en el contrato matrimonial de dicha joven con el zapatero valenciano Antoni Milá. Pocos días más tarde, el 14 de enero de 1452, Armandus de la Capella, "mercator alamanus" residente en Valencia confesaba que Albertus le había pagado 30 florines precio de "decem candelobra lautoni sive de llautó". .

38. APPV, prot. 18416 (1451, agosto 7; noviembre 24; 1452, enero 27).

39. En julio de 1458 , Albertus, en solución a su hijo Joan de Colunya, también "cerdo" y en calidad de tutor de éste y de los otros hijos que tuvo con Raymundeta, su difunta primera esposa, y en atención a la dote de ésta que ascendía a 100 libras, vendió a Joan los bienes muebles de la casa donde ahora habita, tanto de cueros, como de madera y lanas, por valor de 90 libras. A continuación Albertus reconoce tener en comanda dichos bienes de parte de su hijo. Debía tener Albertus otro hijo, homónimo, pues ese mismo día, Albertus de Colunya "cerdo" menor de días, en nombre propio y como a curador de sus hermanos, nombró procuradores a su esposa Esperanza y al notario Pere Guerau. violario con el correero flamenco Andreas de Bruxelles. El 12 de abril de 1451 Albertus fue nombrado procurador por el mercero flamenco Rotlán de Notobart en calidad de heredero de su hermano Luís de Notobart. Ese mismo año también actuó como procurador de Anthonete, hija de maestre Nicholai de Champanya, en el matrimonio de ésta con el valenciano Antoni Milá, que era zapatero de profesión como Albertus. Y un año después mantenía negocios con el mercader alemán Armandus de la Capella. ${ }^{37}$ Incluso años más tarde, el 9 de julio de 1461 Albertus actúa como testigo del contrato matrimonial establecido entre Joana, hija de un agricultor de Cullera, y Sthefanus Alemany, "cerdo" habitante en Valencia. Obsérvese la conjunción de oficio, zapatero, pero también lo interesante del apellido, que puede denotar el posible origen geográfico. Como vemos, conexiones y redes de socialización relativas a la profesión y a la geografía.

En ese sentido, destaca la relación con el también zapatero alemán Ans Alegre. El 7 de agosto de 1451 Ans confesó deber a Albertus la cantidad de 80 libras que éste había pagado por aquel del alquiler de la vivienda y la tienda, así como de menaje de hogar y del precio de ciertos cueros, cantidad que Ans prometió devolver a Albertus cuando fuera requerido por éste. Unos meses más tarde, en noviembre de ese año, Damiata, viuda del sastre de Valencia Johan Steve, se casó en segundas nupcias con Ans, aportando una dote de 70 libras entre ropa, dinero efectivo y joyas. Los testigos del acto fueron todos zapateros, la misma profesión que el contrayente, como Antoni Johan y Joan de Tholosa, pero también actuó como tal Albertus de Colunya. Y poco después, en enero de 1452, Ans atendiendo a que estaba obligado con Albertus con motivo de aquellas 80 libras según el contrato anteriormente referido, y queriendo saldar la deuda, le vendio 120 sueldos censales y anuales pagaderos en dos mitades, precio de dichas 80 libras. ${ }^{38} \mathrm{Da}$ la sensación de que Albertus, afincado en la ciudad desde hacía años, ayudó a su compatriota Ans a establecerse en Valencia. Tenía el mismo oficio y tal vez pudo gestionar sus contactos. Con esa cantidad de moneda Ans pudo surtir su tienda de diferentes tipos de cueros y pudo alquilar su casa, su obrador y equipar su domicilio. A cambio Albertus obtuvo una cómoda renta anual que le proporcionaría el censal contratado por Ans.

Por otro lado, y por lo que respecta a la socialización y lazos de parentesco o familiares, parece ser que Albertus estaba plenamente integrado en la sociedad que lo había acogido. Casado en primeras nupcias con Raymundeta, en 1451 había enviudado. Fruto de ese matrimonio hubo varios hijos, de los que tenemos documentados a Joan de Colunya, con el mismo oficio que su padre, y a Albertus de Colunya el menor, homónimo, y también zapatero de profesión. ${ }^{39}$ Pero Albertus volvió a casarse. Según capítulos matrimoniales del 20 de noviembre de 1453, Albertus padre había contraído segundas nupcias con una mujer llamada Isabel. En ese núcleo familiar, en el que desconocemos si hubo algún nuevo nacimiento, tuvo cabida una joven que fue contratada para servir en la casa, algo muy típico del momento. Así, en octubre de 1457 el labrador valenciano Joan Turcho afirmó con Albertus a su hija Isabel, de 12 años, a servicio doméstico durante 6 años, si bien no se menciona soldada. Una niña de 12 años contratada para servir, y también en hipótesis para llenar el hueco de los hijos.

Pasados unos años, y posiblemente consciente de la proximidad de su óbito, Albertus nombró procurador de sus bienes a su esposa Isabel, el 29 de marzo de 1463. Pocos meses más tarde, el 11 de agosto de ese mismo año Albertus debía de haber fallecido pues su viuda Isabel, y Joan de Colunya "cerdo" hijo de Albertus y de su primera esposa, se comprometen a realizar el inventario de bienes del difunto siguiendo las disposiciones que marca la ley. El inventario se inicia en el comedor de aquella casa que Albertus habitaba en la Parroquia de Santa Caterina de Valencia, casa sita en "lo carrertravesser prop la plaça de la Figuera... Primo, un drap de pinzell...". El inventario no se finaliza pues el notario remite al documento contenido en el notal (manuscrito que no se ha conservado). 
Sin embargo, sí que disponemos del inventario de unos años antes, aquel de 1457 (anexo, documento 1). A través de él podemos aproximarnos un poco más a la vida cotidiana de Albertus. En ese sentido, la arqueología es la principal vía de acceso para el estudio de la cultura material del pasado. Los objetos, los restos, las muestras, etc... localizados en una excavación arqueológica nos informan de los útiles y enseres que rodearon la vida del individuo. Sin embargo, la iconografía, y también la escritura, pueden, en ciertas ocasiones, ofrecer una visión paralela o complementaria de las condiciones materiales de vida y de trabajo de las personas. Una pintura mural o un óleo pueden recoger, visualmente, aspectos contemporáneos al momento de su ejecución pictórica (vestidos, calzados, muebles, vajillas, arquitecturas, herramientas, etc...) independientemente del momento histórico que tratasen de representar. También un texto puede recoger las nomenclaturas de los objetos, su descripción detallada, e incluso, si se trata de un texto que enumera un inventario de bienes, indicar uno tras otro el global de éstos y también su disposición u ordenación en el espacio habitado. Incluso en ocasiones se puede consignar el valor económico que se otorga al bien. Este mundo de los objetos bajomedievales es el que permite acercarnos a la imagen más íntima que tenemos de la vida y las posesiones de las gentes. Y estos objetos se listan claramente, como decimos, a través de los inventarios de bienes.

Una mirada rápida permite ver un mobiliario de bancos, sillas, cajones, cofres, camas y mesas (algunas plegadizas). Es normal que diversos tipos de recipientes hagan las veces de contenedores de todo, tanto de sustancias líquidas (cántaros, jarras, griales) como de materias sólidas (capazos, canastas, cestas, sarriones, talegas). Los útiles de cocina repiten fórmulas muy elementales de aquello que los arqueólogos suelen llamar la típica vajilla de cerámica común de cocina (escudillas, ollas, platos, tarros) acompañados de otros útiles de uso culinario, de madera o metal (crisoles, hierros de cocinar, paellas). La indumentaria reproduce igualmente modelos inmemoriales en función de sexo y edad (calzas, camisas, capas, gorros, faldas, gonelas, velos) pudiendo cambiar la tipología del color o de la materia prima (lino, lana, seda). Mientras, los complementos del hogar dejan entrever ciertas pautas de abrigo y comodidad en la vida doméstica (cojines, cortinas, mantas, sábanas, manteles, colchones y colchas, secamanos, toallas). Paralelamente, en ocasiones se muestran útiles del oficio, acopio de materia prima, herramientas del agro, e incluso cierta posibilidad de armarse (lanzas, lórigas, espadas, yelmos). Y también se puede observar la reserva alimenticia, casi siempre con las menciones al cereal, el vino y el aceite. Además, algunos inventarios pueden mostrarnos la estructura y distribución interna del hábitat (entrada, comedor, habitaciones, bodega, corral, cocina, escritorio, tienda, etc). Pero en conjunto, y para la inmensa mayoría de artesanos, se nos muestra más la pobreza del mobiliario con interiores sin novedades ni decoraciones de lujo. Tan sólo cuentan los conjuntos, la atmósfera general que es sobre todo de trabajo y esfuerzo, de supervivencia más que de confort y ocio, aunque existan (Navarro, 2005a y 2005b).

Aún así en el inventario de Albertus sí cabe destacar, con carácter indiciario, algunas menciones interesantes, como todo aquello referido a su oficio: herramientas ("axons pertallar, formes, coltells, agulletes"), estantes para mostrar la mercancía ("posts, rastells"), la propia variedad merceológica ("tapins, sabates, borceguins, sochs") y su tipología (de hombre, mujer o niño). Pero también la gran cantidad de piezas que le permitiría mostrar una armadura casi completa, o el equipamiento para un rocín, así como numerosas armas, algunas de ellas imponentes (una espada de dos manos o mandoble, ballestas de acero). Como elementos de ocio también hace mención a diversos libros (tal vez de lectura, o memoriales de registro de su actividad artesana), una mesa de juego, e incluso varias jaulas grandes y pequeñas con pájaros cantores en su interior. Finalmente, algunos elementos suntuarios que permiten mostrar trazos culturales o actitudes religiosas, como el "drap de pinzell ab la Passio", un "altar ab sos peus ab ses cubertes rexades e davantal rexat, e un tabernacle ab la ymatge de la Verge Maria, 
e un retaule de la Gloriosa madona Sancta Maria" y otro "drap de pinzell de la stòria de la Verge Maria". Finalmente también se hace mención a un torno para hilar lana, herramienta que tal vez pudo usar su esposa para producir hilo destinado a la importante industria textil valenciana.

\section{Conclusión}

La presencia de comerciantes de origen alemán en la ciudad de Valencia queda patente ya desde las primeras décadas del siglo $\mathrm{XV}$, dando la sensación de un incremento del número de aquellos a lo largo de la segunda mitad de la centuria. Su actividad comercial, consignada en diversos registros escritos, se inscribe en la dinámica general de los territorios de la Corona de Aragón. Sin embargo, quedaba un espacio yermo relativo a la presencia de alemanes en Valencia: el grupo artesano. Nuestra pretensión ha sido dar a conocer, mediante el uso del método de investigación prosopográfico, los primeros datos compilados para estos menestrales germanos durante la primera mitad del siglo XV. A falta de profundizar en los diversos perfiles sociales que podemos encontrar, presentamos como ejemplo la prosopografía de un maestro zapatero, Albertus de Colunya, aproximándonos a la realidad familiar, laboral, y cotidiana, de este artesano.

\section{Textos}

\section{Documento 1.}

1457, septiembre 7. Valencia.

APPV, $n^{\circ}$ 18414. Notario Joan d'Aragó.

Inventario de los bienes que Albertus de Colunya vende a su propia esposa Isabel atendiendo a la dote que ella aportó, y al aumento correspondiente.

Ego Albertus de Colunya, cerdo, vicinus Valencie, considerans et cetera. Ideo gratia et cetera, pro solucione fienda vobis domne Ysabeli uxori mee, de illis octoaginta libris monete Regalium Valencie per vos michi in dotem constitutis tempore nostri matrimoni, et quadraginta libris de augmento pro ut constat instrumento per subscriptum notario recepto die vicesima novembris, anno a Nativitate Domini Millesimo quadringentesimo quinquagesimo tertio. Gratis et cetera, vendo et cetera, vobis dicte uxori mee absente et cetera, bona mobilia que intus domum meam repereiuntur que secuntur preciis et extimacionibus sequentibus. Primo, un artibanch ab sos respatles ab tres caxons quasi nou, de pi, pro una libra decem solidos. Ittem, altre artibanch vell de pi ab dos caxons pro decem solidos. Ítem dos axons de pi per tallar çabates lo hu quasi nou, l.altre vell, e quatre posts de salzerper tallarçabates dessús de poqua valor pro una libra decem solidos. Ittem mes, dos posts de pi perpenjar tapins pro decem solidos. Ítem un rastell perpenjar formes de çabates ab huyit dotzenes de formes de çabates e de tapins pro tribus libras. Ítem, dos parells de enformadores de borzeguins pro sexdecim solidos. Ítem, dues taules petites ab sos peus e una taula larga ab sos peus totes velles de pi pro duodecim solidos. Ítem, tres gerres per tenir vi, les dos de cinch cànters poch mes o menys cascuna, l-altra de tres canters pro septem solidos. Ittem, trenta dotzenes de sochs de fust les deu dotzenes guarnides de cuyro e vint-quatre parells de tapins pro decem libras. Ítem, un taulell de jugar a taules, e sis coltells de tallar çabates e una stora vella e un lancer ab dos lances, e un dall e quatre raspes pro duabus libras. 
Ittem quatorze dotzenes de çabates de home entre negres e tenas e envessades, e una pedra de esmolar larga pro sexdecim libras. Ittem dos dotzenes de çabates de dona e quatre dotzenes de çabates petites de infants e miga dotzena de tapins sotils petits pro tribus libras. Ittem cinch banques de fust ab peus pro quinque solidos. Ittem sis parells de stivals vells equatre parells de borzeguins vells pro una libra decem solidos. Ítem una spasa de dos mans e un llit de quatre posts ab peus de pi tot sotil pro una libra quinque solidos. Ítem una servellera sotil e una engavera brodada e un broquer de ferrer e una coltellina genovesa e una sella ossada negra, un parell de cambals ab sos streps e dos singles e una xaquina de cuyro pro una libra quinque solidos. Ítem un studi de pi ab quatre peus en lo qual hi ha una capça de cuyro gran e altra petita e dos peses de lautó per una libra. Item, dos dotzenes de imatges de terra entre blanques e pintades per una libra. Ítem un gorgeri de gesaran e unes manegues de banya e un punyale un basalarte un guant de ferre e un cabasset ab sivelles dobles deu grosses, pro una libra decem solidos. Item set libres entre petits e grans e altre libre de paper pro una libra. Ittem una magerra per metre diners, e un cove de fust ab sa cuberta ab una dotzena de sponges e una bochaqua de lens pintada de tres bosses, e una finta ab sa bossa castellana pro tredecim solidos. Ítem miga dotzena de ferres per piquar borzequins e altra miga dotzena d-agulletes de picar pro una libra. Item dos artibanchs cascú de tres caxons pro una libra decem solidos. Ittem una taula de quatorze palms de llarch ab sos peus tot de pi, una cadira de roure encaxada e una cadira plegadissa pro una libra decem solidos. Ítem un drap de pinzell ab la Passió e una stora streta pro una libra duobus solidos. Ítem, una gàbia gran ab cinch gàbies petites e una gàbia de callandríe altra gàbia ab una cadernera pro decem solidos. Ittem una caxa gran de salzer e altra prima de salzer e una catiffa petita pro duabus libras. Item, un bassí de lautó e un picher e un torn per filar lana, e dos canelobres de lautó e dos olles de aram, e una caldera de un cànter vella pro duabus libras. Item, dues ballestes una de fust altra de banya, molt sotils, un pavés pintat e un barret de ferro cubert de seda, e un parell de amambrassos e un parell de muscleres, pro una libra octo solidos. Item, dues manetes de ferre ab sos sints, e una tellola ab son sint, e dos carcaxos, e dues spases sotils, e una maça de coure por una libra. Ítem, un altar ab sos peus ab ses cubertes rexades e davantal rexat, e un tabernacle ab la ymatge de la Verge Maria, e un retaule de la Gloriosa madona Sancta Maria, e un rastell pro una libra decem solidos. Ítem un lit de salzer ab cinch posts e peus, màrfega e matalaff vermell e travesser real, pro quatuor libras decem solidos. Item un cortinatge blanch ab ses thovalloles de flocadura blanqua pro quatuor libras. Ítem un artibanch de pi ab dos caxons ab son peu pro duodecim solidos. Ítem una flaçada blava ab figures de blanchets blanchs figurats pro una libra. Ittem una vanova blanqua embotida ab flors de lir pro tribus libras. Item una caxa curta de salzer equatre coffrens vells e un mig coffre ferrat de fulla blanqua pro tribus libras decem solidos. Ítem dues flaçades blanques, una ab listes blaves e vermelles e altra flaçada blava ab listes blaves e vermelles pro duabus libras quinque solidos. Ittem tres parells de lançols de lli pro quatuor libras. İtem tres parells de llançols de stopa de tres teles cascú pro duabus libras. Item quatre coxinals embagats de tot seda pro una libra. Item dos coxins de lli embagats e dos coxins de cothonina de cap, e un parell de thovalles de stopa de quatre alnes cascunes pro una libra. Item un parell de thovalles de lli de quatorze palms poch mes o menys les unes ab listes blaves pro una libra uno solido. Item, quatre thovalles de stopa sotils de quatorze palms cascuna e tres thovallons de stopa sotils e unes thovalles de stopa curtes ab listes blaves e cinch torquaboques de lligrosset por una libra septem solidos. Item, miga dotzena de thovalloles de lli de exugar mans pro septem solidos. Item mes, huyit thovalloles stretes de exugarmans pro septem solidos. Ítem, set camises de home de li e sis panyos pro duabus libras. Item, una camisa de dona ab listes blaves, cinch camises de dona pintades de negre pro una libra decem solidos. Ítem dos parells de mànegues de dona de seda pro duodecim solidos. Íte, tres draps de cap e altre de seda, altre de cothó e unes mànegues de vellut vert, e una bayna de ganivets guarnida d argent pro una libra duobus solidos. Ítem, un llit de quatre posts sotil, màrfega e matalaff blanch e un parell de lançols de stopa tot sotil pro una libra decem solidos. Item un davantal randat de sis alnes pro una libra. Ítem, altre davantal de li de tres alnes e miga pro quinque solidos. Item, altre davantal de tres teles randat per mig pro quinque solidos. Ittem, altre davantal de stopa randat de tres alnes pro quinque solidos. Ítem, una cota negra de hom forrada de blanquet pro duabus libras decem solidos. Ítem un gonell de hom vert forrat de blanquet e altre gonell sotil vert e dos parells de calces de hom, 
unes negres altres rosades de vermell, una clocha negra e un gipó blau de Osteda vell pro quatuor libras quinque solidos. Ítem, un mongil de dona mig usat negre e un mantonet negre de dona, un mongil bruxellat molt sotil e una gonella de dona burella ab perfil e unes faldetes vermelles e dos parells de calces vermelles pro septem libras decem solidos. Item una catiffa morisca e huyit recolzadors pintats blaus e un matalaf blau pro duabus libras duodecim solidos. Item, un drap de pinzell de la stòria de la Verge Maria e una stora sotil pro duodecim solidos. Item un altre llit de cinch posts sotil, matalaff blanch, màrfega, huyit lliures de stopa filada, una caxa sotil, tres plats de stany, sis talladors de fust, un carner de quatre bosses, un canelobre de lautó petit pro una libra decem solidos. Quequidem bona mobilia pro ut superius continetur preciis et extimacionibus precontentis vobis vendo in solutum pro racione dictorum dotis et augmenti cum omnibus juribus et cetera confitens me tenere nomine precario et cetera dans et cetera. Et teneor de eviccione et cetera obligando bona et cetera large et cetera protestor et cetera. Ad hoc autem ego dicta Ysabel acceptans et cetera. Actum Valencie et cetera. Testes Bartholomeus Roqua, notarius et Vincencius Stanyol, assaunator, cives Valencie. 
2 En la actualidad, y conjuntamente con el profesor David Igual de la Universidad de Castilla-La Mancha, estamos preparando un trabajo en el que llevamos a cabo la identificación de artesanos y comerciantes de origen flamenco que actuan en Valencia. Mediante el método de investigación prosopográfico hemos podido documentar ya a más de medio centenar de estos flamencos habitando en la ciudad entre finales del siglo XIV y mediados del siglo XV. Al respecto, algunos autores admiten que las definiciones geográficas (alemán y flamenco) pudieran contener imprecisiones debido a la dificultad de atribuir con precisición la correspondencia de lugar, pues en ocasiones se menciona a un alemán de Flandes, o a un flamenco alemán (Sandri, 1988: 151-153). En Valencia el caso también se observa en los datos prosopográficos ofrecidos por Hinojosa (Hinojosa, 2007). La indefinición tal vez pueda provenir por las actividades propias llevadas a cabo, que interrelacionaban a miembros de ambas geografías. Por ejemplo Martín Van der Beurse (Martí Borsa, o Bossa) "mercator flamenco nunc in dicta civitate degenti presenti, mercator Flanden opidanus ville Brugen pro nunc Valencie mercancionis causa residens", en 1420 sustituía al alemán residente en Barcelona maestro Lambert Dercle, sastre, como procurador de los mercaderes alemanes de la Hansa Teutónica residentes en Brujas Meynardo Vandescena, Johanne Lumich, Luch Scarp y Bertholdo Hemisceda (carta de procura dada en Brujas el 9 de agosto de 1419 ante el burgomaestre y cónsules de dicho lugar), para que en nombre de éstos interviniera ante la curia de Valencia en la cuestión que los enfrentaba con los vizcaínos habitantes de Bermeo Pedro Roiç de Guirra y Otxoa de Roscho, quienes habían capturado una nave de los alemanes llamada Caterina, con sus aperos y útiles. Dichos alemanes facultan a Martín para que pueda litigar en su nombre y llegar a acuerdos y arbitrajes, atendiendo a que se ha buscado ya un árbitro por parte del rey, como es García de Torre, doctor en leyes, comendador de Castellot y consejero real. Archivo del Real Colegio del Corpus Christi de Valencia (APPV), prot. 25305 (1420, marzo 16). (En página 180.)

5 La presencia de un considerable número de alemanes atraídos por el desarrollo de la actividad productiva textil de la lana en Florencia se documenta en el paso del siglo XIV al XV (Franceschi, 1999). En la misma ciudad, el libro registro de legados testamentarios, datable entre 1413 y 1456 , mostraba que el $40 \%$ de los extranjeros allí consignados eran originarios de tierras alemanas. Pero también el listado de 1436 “dell'Ufficio dell'Onestà “ recogía el nombre y origen de 71 prostitutas precisando que 26 provenían de la zona de los Paises Bajos y otras 16 eran de origen alemán, admitiendo que ambas definiciones geográficas pudieran contener imprecisiones debido a la dificultad de atribuir con precisición la correspondencia de lugar (Sandri, 1988: 151-153). El mismo aspecto se muestra en la vertiente adriática, en la ciudad de Venecia, donde tras los estragos de la peste negra, y su endémica presencia en las décadas siguientes, las autoridades legislaron para estabilizar la repoblación y la llegada de inmigrantes, sobre la base probatoria de un período de 15 años para adquirir la condición de ciudadano y con ella los privilegios asociados. Esas concesiones fueron copiadas en los “Libri Commemoriales”, datados entre 1377-1503, que suman 947 casos, de los que sólo el 3,5\% hace referencia a alemanes que quisieron naturalizarse venecianos y gozar así de la ciudadanía. La cifra, oficial, parece ser ínfima al compararse, y complementarse, con los datos obtenidos a través de la búsqueda en protocolos notariales del siglo XV, que permitió documentar 254 testamentos dictados por alemanes, en los que se hacía mención a su vez a albaceas, hijos y herederos (Braunstein, 1984). Como vemos, las motivaciones para emprender el camino migratorio podían ser diversas, al igual que diversas podían ser las características y condición social de los inmigrantes. (En página 181.)

11 Mercader alemán negociante en Valencia, recibe licencia para poder cargar en la nave del portugués Loys Johan, que iba a Flandes, 25 costales de almendras en Denia (Hinojosa, 1982: 163). (En página 184.)

12 Tendero alemán originario de Brabante. En 1432 enviaba arroz a Colliure y Génova. En 1439 importaba mercancías desde Flandes a Valencia que fueron aseguradas por Lluís Blanc y Bernat Guillem. En mayo de 1441 nombró procuradores a Cristóbal Tanchart, de La Esclusa, y al alemán Ulric Gostanç (Hinojosa, 2007: 357). (En página 184.) 
14 Mercader natural de Ravasburch, obispado de Constanza en Alemania. Avecindamiento oficial en Valencia el 29 de mayo de 1433, por 10 años, habitando en la P. S. Caterina (Piles, 1978: 1010). (En página 184.)

15 "Botiguer" natural de Nuremberg del Imperio Alemán. Avecindamiento oficial en Valencia el 13 de marzo de 1448, por 10 años, habitando en la P. S. Joan del Mercat, en la calle de las Monjas Magdalenas (Piles, 1978: 1286). (En página 184.)

16 "Corretger" natural de Colonia, del Imperio Alemán. Avecindamiento en Valencia el 27 de agosto de 1431, por 10 años, habitando en la P. S. Caterina, cerca de la esquina de la Frenería (Piles, 1978: 969). (En página 184.)

17 “Alamani". Difunto esposo de Margarita, quien contrae segundas nupcias con el mercader alemán Joan de Breda. El documento presenta rotura en la página. Aunque se indica que es alemán, también desconocemos si realmente estaba presente en Valencia, o falleció en Alemania y su viuda, trasladada a Valencia posteriormente, contrajo aquí segundas nupcias. Véase la referencia archivística en Breda. (En página 184.)

18 "Mercatore de Alamania presenti in dicta civitate". Margarita de Colunya, viuda de Guriçi Denbós, "alamani", se coloca en matrimonio con Breda, ofreciendo como dote 500 florines (400 en moneda y el resto en ropas y joyas), cantidad que Breda confiesa recibir. Testigo del acto figura Guillermus d’Alamanya, fraile menor de Valencia. APPV, prot. 566 (1413, noviembre 26). (En página 184.)

19 Mercader alemán. Aparece el 9 de mayo de 1417 consignado en el registro de cuentas del mercader flamenco Martí Borsa (Verlinden, 1985: 271). El 2 de abril de 1430, tildado como mercader y ciudadano de Valencia, Rigolf confesaba que Johan de Penyaranda, también mercader de la ciudad, le había satisfecho cierta cantidad como final de cuentas "ut factor et partibus Bruges societatis" que se había constituido entre un tal d'Alepuç mercader, y tras su muerte Joan d'Abella doctor, Simó Cescreus, y el propio Rigolf. APPV, prot. 20700 (1430, abril 2). Este protocolo del notario Ambrosi Alegret está muy deteriorado faltando la mitad de las hojas en línea vertical, por lo que quedan grandes lagunas en la información que podemos obtener sobre nombres, cantidades, etc. (En página 184.)

20 Posiblemente sea el Ubel de Colunya que menciona Hinojosa en 1434 (Hinojosa, 1982: 166). Mercader alemán residente en Valencia. En 1425, Daniel Barceló mercader valenciano, por vía de alquiler, entrega a Abel un obrador franco sito en la partida vulgarmente dicha de la Porta Nova, frente el hospicio donde vive Francesc, hermano de Daniel, frente obrador de los herederos de Joan Bou, y calle pública, por 3 años, a contar desde el próximo 18 de mayo, precio de 13 libras cada año. APPV, prot. 21508 (1425, marzo 2). Albacea testamentario del flamenco Martí Borsa, en mayo de 1429 (Cruselles, 2007: 113). (En página 184.)

21 Mercader alemán residente en Valencia. Es el destinatario de 60 ducados que los venecianos Francesco Vener y Bartolomeo Venturelli han encomendado a los patrones de nave Francesc Doto y Nicolau Benavent. En 1450 figura en una letra de cambio girada desde Barcelona por 120 libras 5 sueldos 9 dineros enviada por Jos Ompis (Jous Hompis), alemán, y su compañía. APPV, prot. 25971 (1446, julio 18), 25958 (1450, octubre 30). Coler está documentado en Valencia desde 1435, siendo factor de la compañía Ravensburger (Jaspert, 2005: 1793). (En página 184.)

23 “Botiguer seu mercator alamano Valencie residente". El 1 de junio de 1463 Guillem Steve, notario de Valencia y su esposa Orfresina confesaron deberle 36 libras precio de 24 piezas de fustán "de mig bou", a pagar en 4 meses. Como garantía del pago le ofrecieron los 266 sueldos 8 dineros censales que al matrimonio le hacía la universidad de Valencia. Días más tarde, el 15 de julio, actuaba como testigo en un acto notarial. APPV, prot. 16706 (1463, junio 1 y julio 15). (En página 184.)

24 “Botiguer seu mercator alamano Valencie residente". El 1 de junio de 1463 Guillem Steve, notario de Valencia y su esposa Orfresina confesaron deberle 36 libras precio de 24 piezas de fustán “de mig 
bou", a pagar en 4 meses. Como garantía del pago le ofrecieron los 266 sueldos 8 dineros censales que al matrimonio le hacía la universidad de Valencia. Días más tarde, el 15 de julio, actuaba como testigo en un acto notarial. APPV, prot. 16706 (1463, junio 1 y julio 15). (En página 184.)

25 APPV, prot. 14091 (1395, octubre 25), prot. 869 (1395, julio 21). También en 1409, el caballero valenciano Guillem Benet confesaba deber al pañero Jaume Monçó 25 libras 15 sueldos "racione panni lane de Flandes diversorum collorarum" cancelándose en 1412. O en 1419, en el inventario de bienes del difunto Antoni d'Alagó, licenciado en leyes ciudadano de Valencia, se consignaba "una cota blava del dit deffunt de verví de Flandes, forrada de vays blanchs" y como bienes de su esposa, "un altre cot e manteta de la dita dona, de verví de Flandes, ferret les mànegues desforrades e la manteta forrada de corderins negres". Prot. 26306 (1409, antes del 11 de septiembre), prot. 25304 (1419, enero 14). (En página 185.)

26 Entre los bienes del mercader valenciano Andreu Lópiç, en 1395, se mencionaban varios paños que formaban parte de la sociedad con el florentino Goro d'Estagio, entre los que se listan “dues peces de drap d'aur de Colunya appellat imperial ab cap negre e altre ab cap blau, ítem una peça d'azeytonínegre brocat d'aur de Colunya ab senyals de lleons". También en 1420, el florentino Paolo de Bartholomeo vendía al florentino Guidoni de Matheo, ambos residentes en Valencia, varios paños de origen florentino, pero también "cuatro pecias imperiales auri de Colonya" estimadas en 32 florines florentinos. APPV, prot. 14091 (1395, julio 3), prot. 27182 (1420, enero 19). (En página 185.)

27 Así por ejemplo, se mencionan: “ítem quatre camisses d'om de tela d'Alamanya pus prima, ítem quatre camisses d'om de tela d'Alamanya pus prima, ítem quatre camisses de la prop dita tela, ítem una camissa d'om de la prop dita tela, ítem quatre camisses d'om, les dues de tela d'Alamanya grosetes, ítem teles d'Alamanya blanques miganteres, peces e scaigs, sis, que tiren net un compte e vint e set alnes, ítem set alnes de tela streta alamanya, ítem teles d'Olandes entre peces e scaigs, sis que tiren setanta alnes e un palm e mig". El día 13 de julio se consignaban "primo mitga dotzena de panyos de drap de tela d'Olanda, ítem cinch panyos del prop dit drap, ítem sis panyos de tela d'Alamanya grossos, ítem sis panyos migancers de teles d'Alamanya, primes, ítem sis panyos de la prop dita tela ab tiretes de seda, ítem sis capells d'om morischs, de tela d'Alamanya grosseta, ítem altres sis capells morischs de la prop dita tela, ítem setze panyos de cosir de tela d'Olanda groseta, ítem tres camisses de fadrí de cosir de tela d'Alamanya, ítem cinch camisses per cosir de hom de tela de Olanda groseta, ítem set capells morischs de hom de tela d'Olanda groseta, ítem set tovalloles de fadrí de teles d'Alamanya, groseta". APPV, prot. 1109 (1429, julio 12, 13 y 15). (En página 185.)

29 "Magistro cerdone alamanus" habitante en Valencia. En agosto de 1451 confesó deber a Albertus de Colunya, "cerdo" de Valencia, 8o libras que en su nombre había pagado por ciertos cueros para su tienda y otras cosas, "tam de cordobans, cabrits, cuyram de soles, moltons, cuyram de çumach, logerium botigue et hostilles domus mee, formes et alia dicte domus et botigie et tam pro raubis cubilium quod pro induendo personam meam", cantidad que Ans prometió devolver a Albertus cuando fuera requerido por éste. Meses más tarde, en noviembre de ese año, Damiata, viuda del sastre de Valencia Johan Steve, se casó en segundas nupcias con Ans, aportando una dote de 70 libras entre ropa, dinero efectivo y joyas. Testigos del acto fueron los “cerdones“ Albertus de Colunya, Anthonius Johan y Johan de Tholosa. En enero de 1452, Ans, atendiendo a que está obligado con Albertus en 80 libras por el contrato anteriormente referido, y queriendo saldar la deuda, le vende 120 sueldos censales pagaderos en dos mitades, precio de dichas 8o libras. APPV, prot. 18416 (1451, agosto 7; noviembre 24; 1452, enero 27). (En página 185.)

34 Argentero alemán residente en Valencia. Difunto ya, el guantero alemán de Zaragoza residente en Valencia Rotlán de Salamó indica tener causa de cesión de Joan respecto a su hermano Gerard de Utrech, difunto doncel alemán, según documentación redactada en Alemania. En 1451, el mercader véneto Daniel Polo ratifica procurador a Joan Palmeri mercader ciudadano de Valencia, presente, para que se ocupe de la cuestión o negocio de "cuiusdam perle sive perla, sive joyell de perla guarnit" existente en la herencia del difunto argentero Joan de Utrech, perla que según dice Daniel era de su propiedad. APPV, prot. 23656 (1450, octubre 26), prot. 18146 (1451, julio 6). (En página 185.) 
35 “Alamany, mestre de fer órguens natural de la vila de Res comorant en València". Contratado con Gabriel de Benviure mercader, y Mateo Livia curtidor, ambos obreros de la iglesia de Santa Creu, para la fabricación de unos órganos desde ese día hasta abril próximo, similares a los que ha hecho en la iglesia de Santa Clara, de cuatro palmos y madera de roble de Flandes, precio de 100 florines. Se pagarán 20 libras al inicio, 15 libras cuando el bastidor esté acabado, y el resto al finalizar el trabajo, pudiendo cobrarse con el estaño y plomo "de tota la canonalla dels órguens vells". Varios días más tarde confiesa que sor Beatriu de Soler, abadesa de Santa Clara, le ha pagado 5 libras precio de los órganos que hizo para aquella iglesia. En abril firma ápoca de 40 libras que le pagan Benviure y Livia por los órganos de Santa Creu. APPV, prot. 23656 (1450, enero 1 y 22; abril 20). (En página 185.) 


\section{Bibliografía}

" Aparici, J. (2016). “Naturales de otros reinos en tierras de la Plana de Castelló durante la edad media”. Seminario Internacional, Identidades urbanas, Corona de Aragón-Italia. Redes económicas, estructuras institucionales, funciones políticas (ss. XIV-XV), Zaragoza, pp. 263-278.

》 Bello, J. M. (1993). “Mercaderes extranjeros en Sevilla en tiempos de los Reyes Católicos". Historia, Instituciones, Documentos, 20. Sevilla, pp. 47-84.

"Braunstein, P. (1984). "Appunti per la storia di una minoranza : la popolazione tedesca di Venezia nel medioevo". Strutture familiari, epidemie, migrazioni nell'Italia medievale, Università di Siena, pp. 511-517.

"Casado, I. (2014). Mercaderes alemanes en la Cataluña de la primera mitad del cuatrocientos: el comercio del azafrán en Barcelona según el "Dret dels Alemanys i saboyans" (14251445). Trabajo de Fin de Máster de la Univ. Barcelona.

" Casado, I. (2014-2015). “Las exportaciones de azafrán en la Barcelona del cuatrocientos: la intervención de los operadores alemanes según el Dret dels alemanys i saboyans (1425-1445)". Acta Historica et Archaeologica, Mediaevalia 32, Barcelona, pp. 579-618.

"Casado, I. (2015). "Las migraciones de elite: la presencia y la actividad comercial de los mercaderes alemanes en la Corona de Aragón (siglo XV)". Actas II Simposio Internacional de Jóvenes Medievalistas, Murcia, pp. 156-176.

"Cruselles, E. (1988-1989). “Jerarquización y especialización de los circuitos mercantiles valencianos (finales del XIV- primera mitad del XV)", Anales de la Universidad de Alicante. Historia Medieval no 7, Alicante, pp. 83-110.

»Cruselles, E. (1998). “El mercado de telas y nuevos paños ligeros en Valencia a finales del siglo XV", Acta historica et archaeologica mediaevalia, 19, Barcelona, pp. 245-272.

"Cruselles, E. (1999). “Las colonias de mercaderes y artesanos extranjeros", Historia de Valencia, Ed. Levante, Valencia, pp. 169-170.

》Cruselles, E. (2007). Los comerciantes valencianos del siglo XV y sus libros de cuentas. Universitat Jaume I. Castelló.

"Diago, M. (2002). "Los mercaderes alemanes en los reinos hispanos durante los siglos bajomedievales: actividad de las grandes compañías en la Corona de Aragón”, España y el Sacro Imperio. Procesos de cambios, influencias y acciones recíprocas en la época de la europeización (s. XI-XIII)", Valladolid, pp. 299-328.

"Franceschi, F. (1999). "I tedeschi e l'arte della lana a Firenze fra Tre e Quattrocento". Dentro la città. Stranieri e realtà urbane nell'Europa dei secoli XII-XVI (G. Rossetti Ed). Nápoles, pp. 277-300.

" Hinojosa, J. (1976). "Sobre mercaderes extrapeninsulares en la Valencia del siglo XV", Saitabi no 26 , Valencia, pp. 59-92.

"Hinojosa, J. (1987). "Mercaderes alemanes en la Valencia del siglo XV: la Gran Compañía de Ravensburg", Anuario de Estudios Medievales, 17 / 1, Barcelona, pp. 455-468.

" Hinojosa, J. (2002). "Intercambios y relaciones entre Valencia y las ciudades marítimas del norte Europeo", Poder y sociedad en la Baja Edad Media Hispánica, Tomo 2, Valladolid, pp. 993-1005.

"Hijonosa, J. (2007). De Valencia a Flandes. La nave della frutta. Generalitat Valenciana. 
Fundació Jaume II el Just. Valencia.

» Igual, D. (1994). “Las galeras mercantiles venecianas y el puerto de Valencia (1391-1534)”, Anuario de Estudios Medievales, 24, Barcelona, pp. 179-205.

" Igual, D. (1995). “La ciudad de Valencia y los toscanos en el Mediterráneo del siglo XV”, Revista d'Història Medieval 6, Valencia, pp. 79-110.

» Igual, D. (1998). Valencia e Italia en el siglo XV. Rutas, mercados y hombres de negocios en el espacio económico del Mediterráneo Occidental. Comité Económico y Social, CV. Fundación Bancaixa, Castelló.

» Iradiel, P. (1986). “En el Mediterráneo occidental peninsular: dominantes y periferias dominadas en la Baja Edad Media”, Areas. Revista de Ciencias Sociales, Murcia, pp. 64-76.

» Iradiel, P., Igual, D., Navarro, G., Aparici, J. (1995). Oficios artesanales y comercio en CasteIlón de la Plana (1371-1527). Fundación Dávalos Flétcher. Castelló.

" Jardí, M. (2006). Mestres entalladors a Barcelona durant la segona meitat del segle XV i primer quart del segle XVI: de la tradició germànica a la producció local. Universitat de Barcelona.

» Jardí, M. (2007-2008). “L'aportació dels escultors alemanys a la producció catalana de retaules de finals del segle XV", Locus Amoenus 9, pp. 79-99.

» Jaspert, N. (2005). “Corporativismo en un entorno extraño. Las cofradías de alemanes en la Corona de Aragón”, XVIII Congrés d'Història de la C. d'Aragó, vol. II, València, pp. $1785-1806$.

» Kellenbenz, H. (1988). “Relaciones comerciales entre Alemania y la costa oriental de España (fines de la edad media hasta el siglo XVIII)", Estudis: Revista de Historia Moderna n- 14 , pp. 245-261.

» López, P. (1976). “Las relaciones comerciales de la C. de Aragón con los alemanes y saboyanos. Dret alemà y Saboyà (1420-1694)”, Saitabi, 26, Valencia, pp. 47-57.

» Llop, M. (1970). “Compañías alemanas en la Valencia del siglo XV”, Diario Levante, Valencia (artículo de prensa publicado el 15 de mayo).

» Mainoni, P. (1982). Mercanti lombardi tra Barcellona e Valenza nel Basso Medievo. Cappelli.

» Martínez, S. (2012). "Producción y mercado de azafrán al sur de Aragón durante el siglo XV: el ejemplo de Muniesa, una aldea del común de Huesa”. Una economía integrada, comercio, instituciones y mercados en Aragón. CEMA, pp. 319-344.

» Mitjà, M. (1958). “Dificultades de la industria y comercio alemanes para abrirse paso en Barcelona hasta 1410”, Gesammelte Aufsätze zur Kulturgeschichte Spaniens, pp. 188-228.

» Mitjà, M. (1962-1963). “El comercio y la industria alemanas en Barcelona de 1410 a 1420". Homenaje a Johannes Vincke, volumen I, pp. 285-319.

» Montiel, G. (2004). Viajar para saber: movilidad y comunicación en las universidades europeas. Ed. Univ. Valencia.

"Navarro, G. (1994). “Los genoveses y el negocio de la seda en Valencia (1457-1512)”. Anuario de Estudios Medievales 24, Barcelona, pp. 201-224.

" Navarro, G. (1997). “Emigrantes castellanos en la sedería de Valencia (1479-1524)”. XV Congreso de Historia de la C. de Aragón, volumen II, Jaca, pp. 249-267.

» Navarro, G. (1999). Los orígenes de la sedería valenciana. Siglos XV-XVI. Ajuntament de Valencia. Valencia.

» Navarro, G. (2005a). “Los artesanos aragoneses y valencianos del siglo XV. Prácticas sociales comparadas buscando un guión de vida”. XVIII Congrés d'Història de la Corona 
d'Aragó, volumen I, Valencia, pp. 1077-1088.

» Navarro, G. (2005b). "La cultura material de los artesanos castellonenses en el siglo XV”. Boletín de la Sociedad Castellonense de Cultura, 81, Castelló, pp. 405-422.

» Navarro, G. (2009). "La presencia de grupos extranjeros en la Corona de Aragón (ss. XIII-XV)", La Corona de Aragón en el centro de su historia. 1208-1458. Aspectos económicos y sociales, Zaragoza, pp. 161-19o.

»NAVARRO, G. (2016). “Italianos, franceses y alemanes en la Zaragoza de los Reyes Católicos (1479-1516)”. Seminario Internacional, Identidades urbanas, Corona de Aragón-Italia. Redes económicas, estructuras institucionales, funciones políticas (ss. XIV-XV), Zaragoza, pp. 245-262.

» Navarro, G; Igual, D; Aparici, J. (1999). “Los inmigrantes y sus formas de inserción social en el sistema urbano del Reino de Valencia (siglos XIV-XVI)”. Revista d'Història Medieval 10, Universitat de València, pp. 161-198.

» Piles, P. (1978). La repoblación de Valencia a través de los “llibres de avehinaments" (14001449). Ed. Ayuntamiento de Valencia.

» Puyol, J. (1924). Viaje por España y Portugal en los años 1494 y 1495 (Jerónimo Münzer). Boletín de la Real Academia de la Historia.

» Rubió, J. (1993). “Integración de los impresores alemanes en la vida social y económica de Cataluña y Valencia en los siglos XV-XVI”, Llibreters i impressors a la Corona d'Aragó, vol. 11, Edicions de L'Abadia de Montserrat, pp. 215-243.

»Salicrú, R. (1995). El tràfic de mercaderies a Barcelona segons els comptes de la lleuda de Mediona (febrer 1434). Consejo Superior de Investigaciones Científicas, Barcelona.

»Sandri, L. (1988). “Stranieri e forestieri nella Firenze del Quattrocento attraverso i libri di ricordi e di entrata e uscita degli ospedali cittadini”. Foestieri e stranieri nelle città bassomedievali, Florencia, pp. 149-161.

"Schulte, A. (1923). Geschichte der Grossen Ravensburger Handelsgesellschaft (1380-1530). Berlín, (facsímil disponible electrónicamente en red).

» Vaquer, O. (1995). “Immigrants a Mallorca a la segona meitat del segle XV”, Boletín de la Sociedad Arqueológica Luliana, nº 51, Mallorca, pp.125-140.

»Verlinden, C. (1985). “El registre del mercader de Bruges Martin Van der Beurse (14141427)”, València, un mercat medieval, Diputació de València, pp. 265-275. 
